\title{
The Anomeric Nature of Glucose and Its Implications on Its Analyses and the Influence of Diet: Are Routine Glycaemia Measurements Reliable Enough?
}

\author{
Laia Oliva a, b, Jose Antonio Fernandez-Lopez ${ }^{\mathrm{a}, \mathrm{b}, \mathrm{c}}$, Xavier Remesar ${ }^{\mathrm{a}, \mathrm{b}, \mathrm{c}, \mathrm{d}}$, \\ Marià Alemany $\mathrm{a}, \mathrm{b}, \mathrm{c}, \mathrm{d}$
}

\begin{abstract}
Background: Glucose is the main inter-organ energy supplying metabolite in humans and other vertebrates. In clinical analyses, its measurement is probably the most performed and used for diagnostic, monitoring and control of the physiological status. However, glucose chemical structure, specially its anomeric forms $(\alpha / \beta)$, may deeply interfere in their own analyses, often resulting in misleading results.
\end{abstract}

Methods: These effects on glucose estimation were studied by using a common glucose oxidase/peroxidase based method, in the presence or absence of added mutarotase, which speeds up the $\alpha / \beta$ conversion rate. Glucose concentrations were measured in pure standards and plasma samples from control and cafeteria diet-fed rats.

Results: The addition of mutarotase resulted in higher glucose readings, independently of glucose concentration and its initial anomeric proportions in the sample. In the absence of mutarotase, cafeteriafed rats had higher glucose levels than controls, but the differences disappeared in its presence, because under experimental conditions, a proportion of the $\alpha$-anomer was not isomerized and thus was not measured.

Conclusions: Diet altered the proportion of anomers, suggesting that glucose usage by physiological processes affects the anomers' ratio and may have an important metabolic meaning, which deserves a detailed study in addition to the need to correct the methods in use to obtain real "total glucose" readings.

Manuscript submitted May 17, 2019, accepted May 31, 2019

aDepartment of Biochemistry and Molecular Biomedicine, Faculty of Biology, University of Barcelona, Barcelona, Spain

bInstitute of Biomedicine, University of Barcelona, Barcelona, Spain

${ }^{\mathrm{c} C e n t r o}$ de Investigacion Biomedica en Red (CIBER), Obesity and Nutrition, Barcelona, Spain

${ }^{\mathrm{d} C o r r e s p o n d i n g ~ A u t h o r s: ~ M a r i a ̀ ~ A l e m a n y, ~ D e p a r t m e n t ~ o f ~ B i o c h e m i s t r y ~ a n d ~}$ Molecular Biomedicine, Faculty of Biology, University of Barcelona, Av. Diagonal 643,08028 Barcelona, Spain. Email: malemany@ub.edu; Xavier Remesar, Department of Biochemistry and Molecular Biomedicine, Faculty of Biology, University of Barcelona, Av. Diagonal 643, 08028 Barcelona, Spain. Email: xremesar@ub.edu

doi: https://doi.org/10.14740/jem555
Keywords: Glucose measurement; Glucose anomers; Mutarotase; Glycemia

\section{Introduction}

In humans, and in most vertebrates, glucose is considered the main inter-organ energy substrate. Consequently, its levels are highly regulated and monitored. We often take for granted the precision and validity of the methods used for its measurement. However, most methods are not fully reliable [1], and thus, most experimental glucose measures may not actually reflect the true glucose levels. Given its relevance, we question whether routine measures suffice to build upon critical decisions on diagnostic, control and treatment of malnutrition, diabetes, metabolic syndrome and so on.

In the (near) past, glucose was measured chemically, using its reducing power to develop colorimetric procedures (e.g. Fehling, Benedict, Nelson-Somogyi, etc.) [2, 3]; the main problems of their use were the need for large samples, low sensitivity, chemical interference, and, especially, lack of specificity. The use of enzymatic methods solved the specificity question, and often required smaller samples [4]. The most effective methods were those based on the use of paired enzymes, such as hexokinase/glucose-6P dehydrogenase [5] or glucose oxidase/peroxidase (GOxP) [6]. The former, is quite specific, with good linearity, sensitive and precise for glucose determination [7], although it may be affected by other sugars, limiting somehow its full applicability $[5,8]$. The other main method (GOxP) is, at present, the most commonly used method for glucose because of its easy use, resilience, precision and specificity [7]; and more importantly, its enzymes do not react (theoretically) with other monosaccharides [9]. However, reducing agents such as ascorbate, bilirubin or urate may interfere [10]. A powerful factor modifying the measurements (often ignored) is the almost omnipresent catalase. Nevertheless, the most critical problem of the method is that $\beta$-D-glucose: oxygen-1-oxidoreductase (EC 1.1.3.4) acts only on the $\beta$-Dpyranose anomer of glucose [11]. The widespread use of these methods, however, relies on its cheapness and robustness. The coupled enzymes are easy to produce and are more resistant to extreme $\mathrm{pH}$, ion strength and temperature range variations 


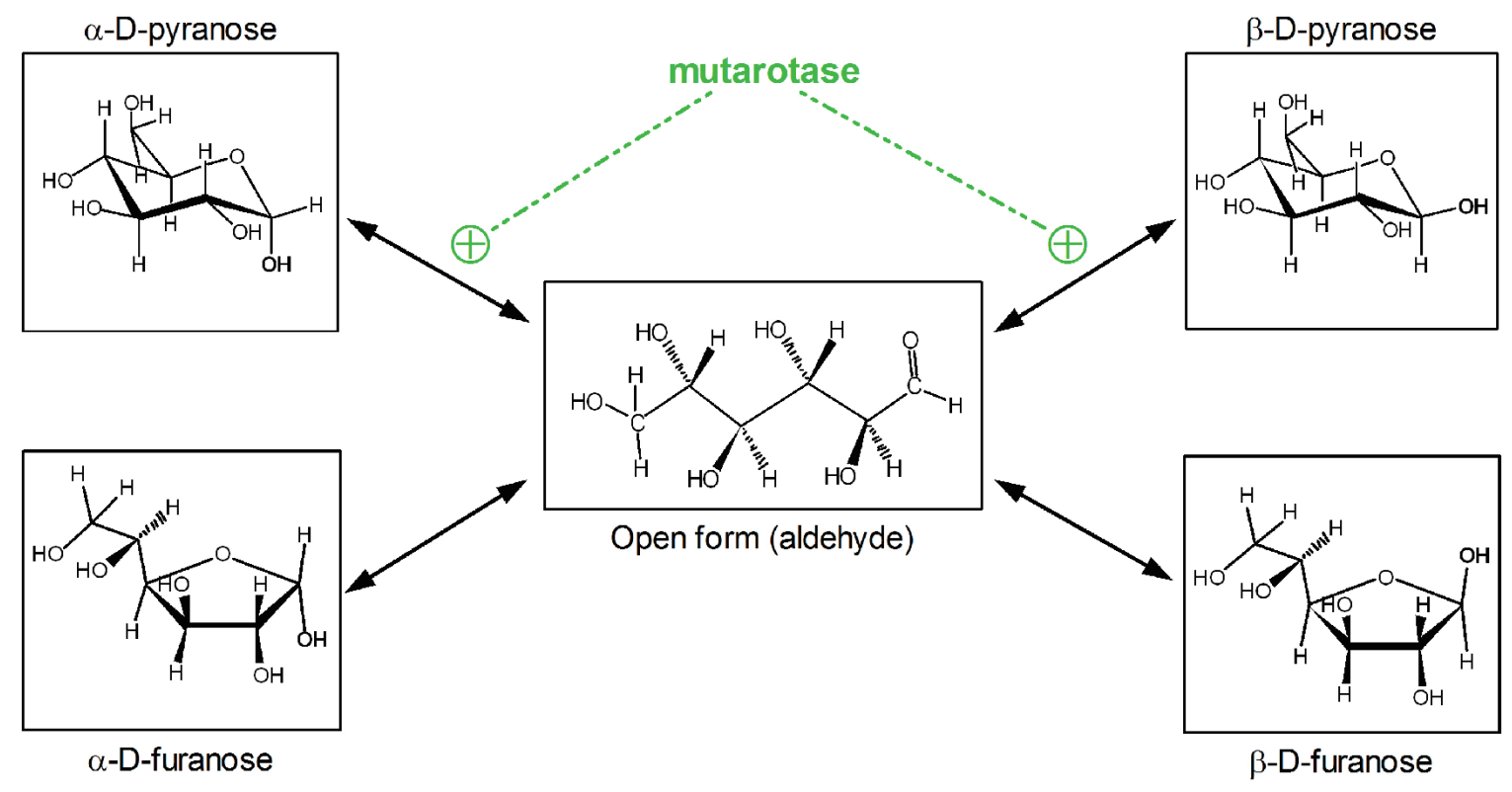

Figure 1. Anomeric forms of glucose in solution and its spontaneous or facilitated interconversions.

than other possible alternatives $[9,12]$. Its extension is largely based on the widespread availability of enzymes and adaptation to systems, platforms and other technical developments [12]. They have lowered the cost, time and need of specialized laboratory equipment, allowing their portability, instant response and miniaturization.

In recent decades, powerful separation methods (i.e. those based on mass spectrometry) have been developed $[13,14]$ for investigation. However, slowly extending metabolomic studies showed that $\alpha$ - and $\beta$-D-glucose anomers are both routinely found in biological samples [15]. The absence of reliable quantitative data usually hampers the interpretation of these results.

Free or saccharide-incorporated glucose is regularly found in the more stable cyclic form. Glucose anomeric carbon (C1) forms a hemiacetalic bond with C5 (pyranose cycle) or C4 (furanose cycle) hydroxyl groups [16]. For hexoses, pyranose forms predominate at room temperature since they are thermodynamically more stable followed by the less stable furanoses; open chain is found only in a small proportion.

The spontaneous closing of the ring via hemiacetalic bond results in an additional source of isomery on the anomeric carbon (C1) ( $\alpha$ or $\beta$ configurations). Most of solid crystalline glucose (i.e. obtained from starch) is in the $\alpha$-D-glucopyranose form. However, when dissolved in water yields a mixture of the open-chain form (aldehyde) and its four cyclic isomers (Fig. 1). In plasma, D-glucose is found essentially as a mixture of two anomers (roughly one-third of $\alpha$-D-glucopyranose and about two-thirds as $\beta$-D glucopyranose), with practically no furanose forms $[16,17]$. The interconversion between open-chain aldehyde and ring forms is fast, and is affected by the medium conditions. Thus, any aldose may react, in practice, within a short time frame as if all of it were in the open aldehyde form [17].

Hexokinase (EC 2.7.1.1) transfers a phosphate group from adenosine triphosphate (ATP) to aldo- or ketohexoses, forming the corresponding phosphate ester in C6. This carbon is acces- sible in both glucose anomeric forms; thus hexokinase may phosphorylate either $\alpha$ - or $\beta$-D-glucose [8, 18, 19], producing the corresponding anomeric forms of glucopyranose-6P. However, yeast glucose-6-P dehydrogenase (the enzyme most commonly used in glucose analysis kits) acts specifically on $\beta$-D-glucose-6-P only. The spontaneous anomerization rate of $\alpha$-D-glucopyranose-6-P at physiological $\mathrm{pH}$ is two-fold faster than that of free glucose $[7,19]$. Thus, the hexokinase/glucose 6-P dehydrogenase enzyme pair has often been used successfully for quantitative glucose determination, under adequate medium conditions $[5,19]$. The high cost and the conditions for analysis have limited the use of this paired-enzyme approach (Fig. 2).

When solid ( $\alpha$-D-glucose) is dissolved to prepare standards, it tends to achieve an equilibrium with somewhat more $\beta$ - than $\alpha$-isomer [20]. When both, standards and samples, are exposed to glucose oxidase, the enzyme oxidizes only $\beta$-Dglucopyranose, whilst the $\alpha$-anomer needs to be previously isomerized before oxidation. This interconversion is rather slow at physiological $\mathrm{pH}$ [21], although the widespread presence in biological systems of a specific enzyme, mutarotase (aldose 1-epimerase: EC 5.1.3.3) [22], speeds up the $\alpha-\beta$ interconversion. Absent, insufficient (or variable) natural mutarotase, as is obviously the case of deproteinized samples, may result in a potentially underestimation of "total" (for "true") glucose. This is due to an incomplete conversion of $\alpha$-D-glucopyranose to the $\beta$-D isomer in time for its oxidation during the analytical process [23]. The addition of mutarotase to the medium $[23,24]$, accelerates the interconversion, and increases the proportion of measured glucose. In the practice, however, most current methods "measure" only a large, albeit unspecified, portion of the actual glucose present in the sample. This problem is often overlooked too because the glucose in biological samples is compared with standards (often just prepared), which anomer proportion (equilibrium) is also af- 


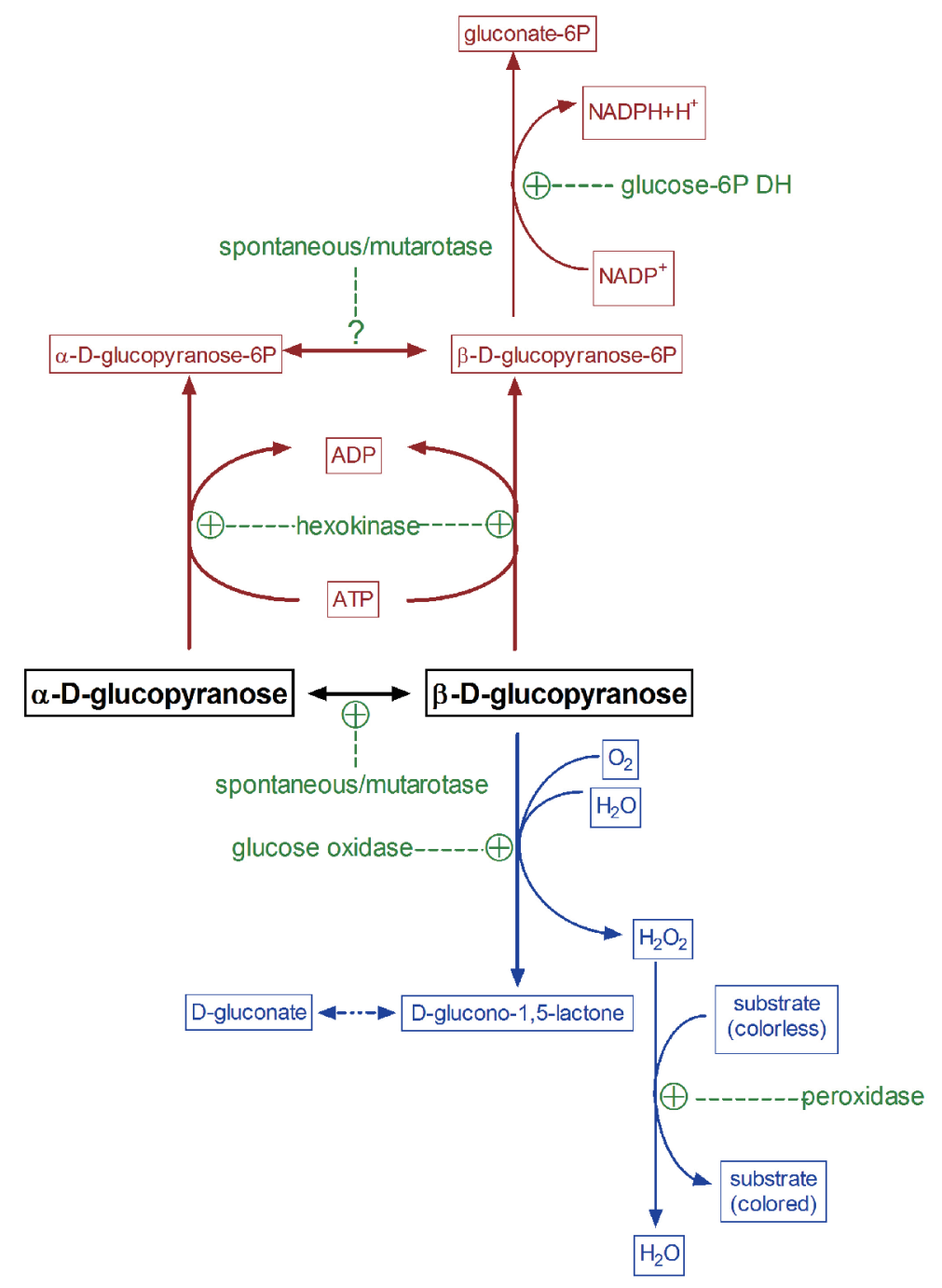

Figure 2. Common paired enzymatic reactions used in the specific measurement of glucose. Hexokinase/glucose 6-P dehydrogenase reaction is represented in dark red, glucose oxidase/peroxidase in blue, and all enzymes involved in green.

fected by time, $\mathrm{pH}$, temperature, etc.

The existence of these problems is well known (textbook material) $[25,26]$, but surprisingly, it is seldom, discussed or corrected. This widespread ellipsis results in the scarcity of reliable quantitative data on glucose levels, which may seriously compromise serial or comparative studies. In order to get some insight as to the range of changes expectable from the sources of variability indicated in the previous sections, we designed a short series of experiments to show the modulatory effects of mutarotase on glucose analysis and the eventual advantages of its regular use.

\section{Materials and Methods}

\section{Samples}

Standard glucose solutions were just prepared D-glucose (Sig-
ma-Aldrich, St Louis, MO, USA) standard solution (0, 2.5, 5.0, $10 \mathrm{mM})$. No differences were observed with the standards provided with the kits after storing our standards overnight. The effect of different concentrations of mutarotase (\#136A5000; Calzyme, San Luis Obispo, CA, USA; specific activity 75 nkat/g protein) was tested with standard solutions.

All animal handling procedures and the experimental setup were carried out in accordance with the animal handling guidelines of the European, Spanish and Catalan Authorities. The Committee on Animal Experimentation of the University of Barcelona authorized the specific procedures used (\#DAAM 6911). Institutional Review Board Approval was not required at the University of Barcelona

Samples of 10-week-old female and male Wistar rats (Janvier, le Genest Saint-Isle, France) from a study carried out by our group [27] were used for the analysis of plasma glucose levels. The animals were randomly divided in two groups $(n=$ 6 for each sex) and were fed ad libitum with either a standard diet or a hyperglycemia-inducing simplified cafeteria diet [28, 


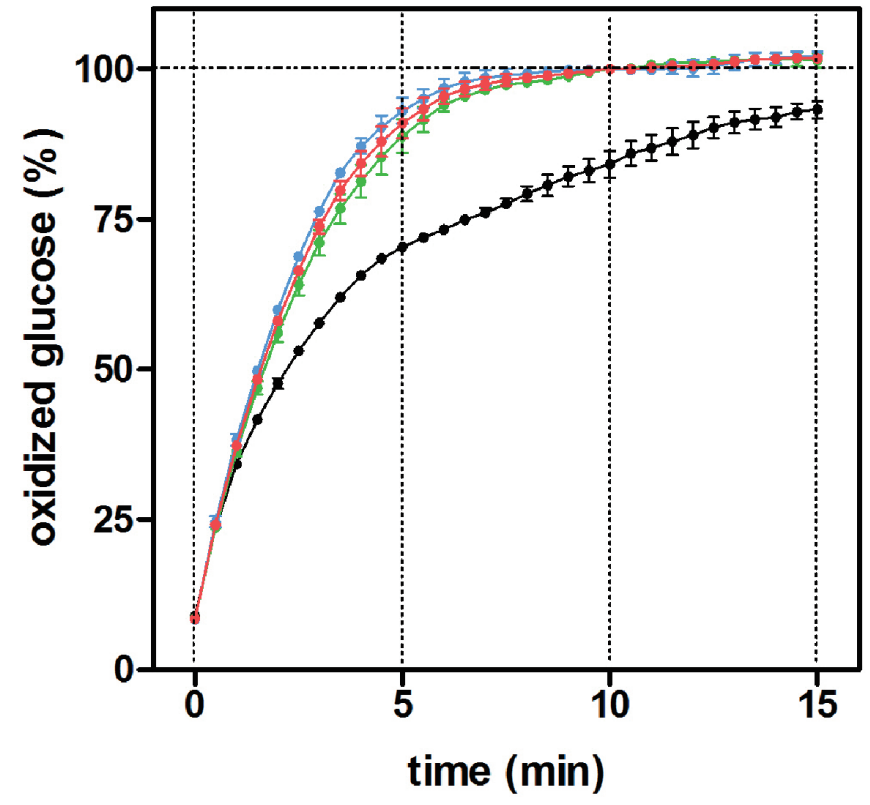

Figure 3. Percentage of oxidized glucose with incubation time in the presence of varying mutarotase concentrations, using a glucose oxidase/peroxidase method. The data (mean \pm SEM) are expressed as of an estimated percentage of oxidized glucose of 10 replicates obtained from a $10 \mathrm{mM}$-D-glucose standard. Black circles: absence of mutarotase; green circles: $0.3 \mathrm{nkat} / \mathrm{L}$ of mutarotase; red circles: $0.5 \mathrm{nkat} / \mathrm{L}$ and blue circles: 0.7 nkat/L.

$29]$ for 30 days. All animals had free access to water. The rats were housed (in same-sex pairs) under standard conditions. On day 30 , at the beginning of light cycle, the rats were anesthetized with isoflurane and then killed by exsanguination through the exposed aorta using a dry-heparinized syringe. Plasma was obtained by centrifugation and kept at $-20^{\circ} \mathrm{C}$ until processed.

\section{Analytical procedure}

Mutarotase solutions were prepared just before each experiment $(0.3,0.5$, and $0.7 \mathrm{nkat} / \mathrm{L})$. Glucose standards were also prepared fresh a couple of hours before measurement of glucose. Standards and samples were analyzed using a glucose oxidase/peroxidase kit (\#11504; Biosystems, Barcelona, Spain). In all cases, measurements were duplicated, one series receiving $250 \mu \mathrm{L}$ of reagent and the other the same volume with added mutarotase. Samples, blanks and standards were incubated at $30^{\circ} \mathrm{C}$ in 96 -well plates. The changes in absorbance at $490 \mathrm{~nm}$ were measured at $30 \mathrm{~s}$ intervals for $15 \mathrm{~min}$ (or up to stabilization) using a plate reader spectrophotometer (ELx808 Ultra Microplate Reader, Biotek, Winooski, VT, USA).

\section{Statistics}

Statistical comparison between groups was carried out using one- or two-way ANOVA analyses, and the Bonferroni posthoc test for further differences between specific groups, using
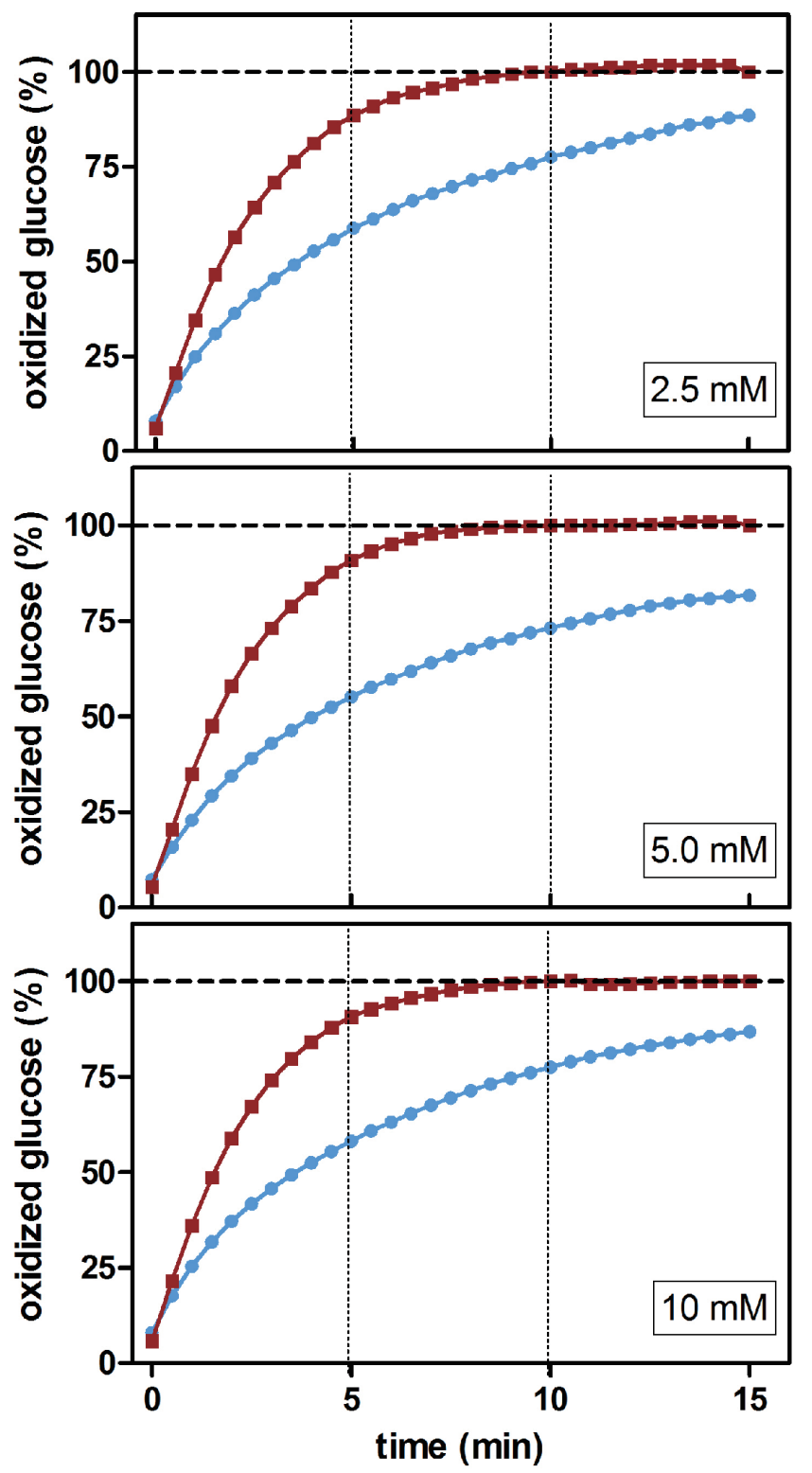

Figure 4. Estimated percentage of glucose oxidized during incubation at different glucose concentrations using a glucose/oxidase assay in the presence/absence of mutarotase. The data are expressed as an estimated percentage of oxidized glucose (calculated from the absorbance of the combined reaction). Data related to absence of mutarotase are represented in blue (line and circles); the data for mutarotase (0.5 nkat/L) are shown in red (line and squares).

the Prism 5 program (GraphPad Software, La Jolla, CA, USA).

\section{Results}

The effects of different mutarotase concentrations on the oxidized glucose percentage using a pure D-glucose standard (10 $\mathrm{mM}$ ) are shown in Figure 3. The presence (in excess) of mutarotase was found to speed-up the reaction, providing a complete 


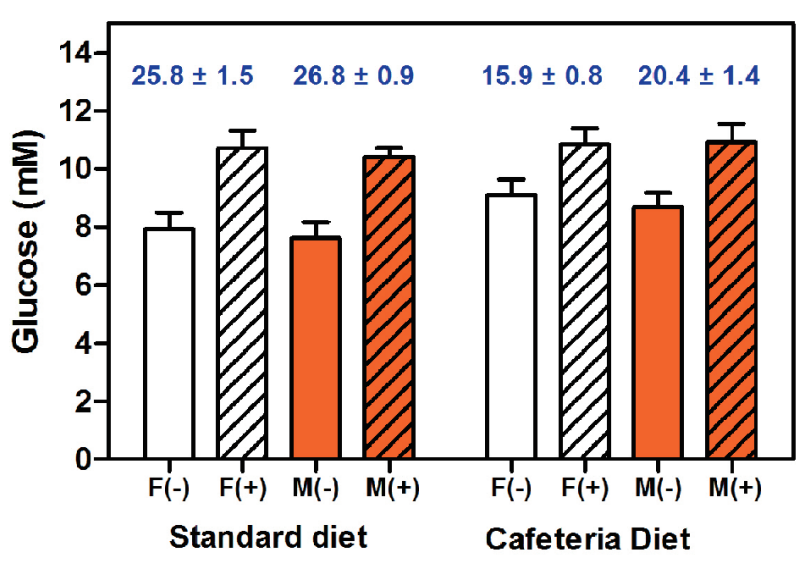

Figure 5. Plasma glucose concentrations of female and male rats fed with either standard chow or cafeteria diet. Glucose was measured with a glucose oxidase/peroxidase method in the absence or presence of added mutarotase. The data are expressed as mean \pm SEM of six animals per group. White bars: females (F), orange bars: males (M). Results obtained in the presence of mutarotase $(+)$ are shown as dashed columns; open columns have been used for the groups measurements in absence (-) of mutarotase. The numbers in blue at the top of each pair of same-sex and -diet columns show the estimated percentage of non-measured a-glucose anomer, as a consequence of the absence of (enough) mutarotase. Statistical analysis of the differences between groups was done using two-way ANOVA. Significant differences were found between absence/presence of mutarotase $(P<0.0001)$. Diet elicited significant statistical differences only in the absence of mutarotase $(P=0.0477)$. Significant differences of unmeasured $\alpha$-anomer were found between control and cafeteria groups $(P<0.0001)$. No differences were found for sex.

oxidation of glucose (the curve became asymptotic before 10 min of incubation, the method-established incubation time). The amount of mutarotase used changed little the form of the curves. However, in the absence of added mutarotase, the time required to achieve a similar reading of glucose levels was dilated up to $15 \mathrm{~min}$. The absence of mutarotase implies that not all the glucose was oxidized (measured), and consequently the overall concentration was underestimated. Mutarotase addition did not affect the readings of buffer blanks. Further analyses were performed using a fixed mutarotase concentration of $0.5 \mathrm{nkat} / \mathrm{L}$, derived from this experiment.

The effects of mutarotase were assessed using different glucose concentration standards (Fig. 4). Eventually, all Dglucose seemed to be completely converted to $\beta$-D-glucose (and then oxidized) in the presence of mutarotase. At $10 \mathrm{~min}$ of incubation in the absence of added mutarotase, a significant part $(25 \pm 1 \%, \mathrm{P}<0.0037)$ of the initial $\mathrm{D}$-glucose remained unmeasured due to the slowness of the process of spontaneous equilibrium under the (common) experimental conditions used. The profiles obtained using three different glucose concentrations were almost identical. These results showed, as expected, that the isomeric ratio of glucose was independent of its concentration. Thus, the actual magnitude of the differences obtained from relative data may result in marked differences when translated to absolute concentrations.

Figure 5 shows the comparative values of plasma glucose concentrations of adult female and male rats fed with either standard or cafeteria diet, measured in the presence/absence of added mutarotase. In all cases, higher absorbances, translated also into higher plasma glucose concentrations, were found in the presence of mutarotase. On this small sample, no significant differences were found for sex. Nevertheless, in the absence of mutarotase, diet elicited borderline significant differences. This is a common occurrence in the literature, since cafeteria-fed rats are considered hyperglycemic when compared to controls fed chow diet.

The higher glucose concentrations of cafeteria fed rats using the non-mutarotase data, compared with standard diet-fed rats, disappeared when mutarotase was present. The estimated $\alpha$-D-glucose proportion (i.e. non-oxidized glucose remnants at the end of the analysis) of standard-fed rat plasma (10 min incubation with the coupled enzymes) was similar to that found in standard glucose solutions, being in both situations 1.5 -fold higher than that estimated for cafeteria fed rats. The fact that the method of measurement of glucose was apparently "more efficient" in cafeteria rats than in controls, suggests the existence of a different initial proportion of $\alpha / \beta$ glucose anomers. This fact elicits the question of the probable differential disposal rates of glucose anomers depending on diet (or pathologies) related to diet modulation of substrate energy utilization.

Another series of plasma samples were deproteinized using the classic Somogyi method [30], in order to eliminate any possible effect of pre-existing plasma mutarotase [21]. This procedure which was widely used in the past for deproteinization was used because the exposure to extreme $\mathrm{pH}$, heat or residual chemicals was minimal before analysis of glucose levels. No differences in the levels of glucose were observed between direct plasma and deproteinized samples (data not shown), suggesting that the assumption of a "sufficient" presence of mutarotase in natural plasma was not enough to minimize (not even fractionally decrease) the analytical problem of slow interconversion between glucose anomers.

\section{Discussion}

The presence of two main glucose isoforms in plasma and tissues causes differences in reactivity, metabolic use and disposal. Anomeric proportions of glucose in plasma and tissues tend to an $\alpha / \beta$ equilibrium, although $\beta$-D-glucose proportion is usually higher [16]. The predominance of the $\beta$-anomer may initially suggest a higher utilization of the $\alpha$-anomer, although, the actual (preferred or exclusive) utilization of glucose anomers in metabolic processes has been sparsely studied. Initially, $\alpha$-D-glucose was proposed as a signal for D-glucose sensing cells (e.g. $\alpha$ - and $\beta$-Langerhans cells and taste buds cells) while $\beta$-D-glucose has been proposed as main substrate for energy production in a number of cells and tissues [21]. Later on, several authors found that different tissues showed specific preferences for transport or metabolization of the $\alpha$ - or $\beta$-anomers [31]. Thus, liver [32], pancreas $\beta$-cells [33], skeletal muscle or adipose tissue [34] seem to prefer $\alpha$-D-glucose, while brain [35, 36], retina [37], erythrocytes and lens cells $[31,38]$ were found to preferably take up $\beta$-D-glucose.

These fragmentary findings emphasized the existence of 
a tissue-specific physiology of anomer glucose transport, hinting that cells expressing GLUT1 or GLUT3 may prefer the $\beta$-anomer and those expressing GLUT2 or GLUT4 may prefer the $\alpha$-form [31]. However, we have not found studies assessing the anomer preferences for the highly regulated GLUT4 transporter. Recent analyses, however, suggest that in some situations glucose anomerization may not be necessary for structure recognition by GLUTs $[39,40]$, since in red blood cells, glucose transporter GLUT1 has been found to transport $\alpha$ - and $\beta$-glucose with similar efficiency [41]. Nevertheless, this question may be largely rhetorical, since red blood cells have mutarotase bound to membranes and hemoglobin [41] thus facilitating a faster interconversion between anomers, speeding glucose disposal for the cell's own metabolic use. Notwithstanding, glucose needs of mammal red cells are low compared with "standard" nucleated cells, thus enhancing the relative importance of mutarotase.

Plasma mutarotase is assumed to speed up the interconversion between hexose anomers [22], but we found no effects at all, i.e. no differences using fresh or deproteinized plasma. Previous studies confirmed that the addition of mutarotase to glucose oxidase-based methods increased the glucose readings of varied experimental samples [23, 24]. We can assume that plasma mutarotase [21] (if any functional activity is present) can hardly help significantly speed up the reactions to allow for "true" glucose results. In the present study, we have found that the addition of enough mutarotase to the coupled glucose oxidase/peroxidase enzymes for the measurement of glucose allowed a sufficiently rapid anomeric interconversion to get a complete oxidation of glucose, resulting in "higher" (in fact closer to reality) measurements of glucose, independently of its concentration within the method range.

Physiological glucose concentration is (assumedly) a well-known entity, around $5-6 \mathrm{mM}$ for rats. In our study, the animals were (necessarily) anesthetized with isoflurane, a hyperglycemic agent [42], which may explain the relatively high values found, specially, in standard diet fed rats. In fact, they were even higher when mutarotase allowed a more accurate estimation. The values obtained were higher than those assumed as physiological, even when anesthesia do not interfere [29], and strongly hint at a generalized and systematic underestimation of glycemia.

Cafeteria diets are widely used as a non-stressing method to induce overfeeding and excessive energy intake, inducing obesity and chronic hyperglycemia as part of the development of metabolic syndrome [43]. The significant differences found in glucose anomer proportion between standard (assumedly physiological glycemia) and that of cafeteria fed rats (assumedly altered) suggest an alteration of the $\alpha / \beta$ anomer equilibrium in plasma. These changed anomer proportions can affect (in an undetermined way and extent) glucose measurements when performed in absence of mutarotase. This unexpected finding may further compound the series of unknown factors when compared to the data of "standards" of pure glucose. The consequences may be deeply misleading with respect to the evaluation of physiological status, and diagnosis.

The presence of different anomeric forms of glucose, in biological fluids may be a consequence of different rates of metabolization, and the unknown entity of how much mutaro- tation takes effect in biological samples, either by mutarotase, or spontaneously depending on time, storage, etc. These factors may provide additional insight on how glucose is used. The bioavailability of anomeric forms of an aldose may deeply affect the ability of enzymes (and complete biological systems) to use them as substrates. Glucose is a key inter-organ substrate, in practical terms; the effectiveness of the systems acting on glucose (transporters, kinases) will be influenced by the total glucose levels but also by the proportions of its anomeric forms (i.e. glucose available for the cell or system). Unfortunately, this factor is almost systematically overlooked, ignored or dismissed.

We have routinely added mutarotase to our analyses of glucose in the last years [44-47]. The wide differences observed in our studies using different diets must be now contemplated from a different point of view, since we now know that most studies of glycemia are (probably) underestimations of the true values, the problem is that we do not know which ones and in which proportion. The finding that diet may change the anomeric proportion is in fact much more disturbing, since an old line of work (metabolic specificity of glucose anomer utilization) may be asked to return from practical oblivion. First, transporter and enzyme preferences or specificities should be checked, followed by an analysis in depth of the effects of diet, since our data show clearly that underestimation of glucose levels may depend ultimately on diet (or inflammation).

In conclusion, the addition of sufficient mutarotase allows the common glucose oxidase/peroxidase methods to account for practically all glucose present in the samples irrespective of their initial anomeric form. This procedure should be made extensive to standards. The results shown here hint at a variable underestimation of glucose levels using (at least) one of the most common enzymatic methods. It is imperative to revise these methods in order to obtain accurate values; and thus allow the analysis of possible metabolic differences of anomer specificity handling under physiological and pathological situations. The need for easy to perform quantitative anomeric glucose analyses becomes another obviously necessary step to clarify most of the present day available data, which reliability may be suspect because of the considerable extent of result variations and uncontrolled factors described in the present study.

\section{Acknowledgments}

No special acknowledgements are expressed.

\section{Financial Disclosure}

This research did not receive any funding. Part of the expenses was covered by the University of Barcelona as employer, and the rest by the researchers themselves.

\section{Conflict of Interest}

The Authors declare no conflict of interests. 


\section{Informed Consent}

Not applicable

\section{Author Contributions}

Concept and overall design, analysis and redaction (MA); ideas and experimental design details (all Authors); experimental work and data analysis (LO); bibliography (LO, MA); provision of samples and materials, administration and budget (XR); revision and statistics (JAFL); general discussion and revision of drafts (all authors). XR and JAFL are the directors of LO PhD thesis, from which this study is a methodological part.

\section{References}

1. Vashist SK. Non-invasive glucose monitoring technology in diabetes management: a review. Anal Chim Acta. 2012;750:16-27.

2. Benedict SR. The analysis of whole blood. 2. The determination of sugar and of saccharoids (non-fermentable copper-reducing substances). Journal of Biological Chemistry. 1931;92:141-159.

3. Nelson N. A photometric adaptation of the Somogyi method for the determination of glucose. Journal of Biological Chemistry. 1944;153(2):375-380.

4. Neeley WE. Simple automated determination of serum or plasma glucose by a hexokinase-glucose- 6 -phosphate dehydrogenase method. Clin Chem. 1972;18(6):509-515.

5. Carroll JJ, Smith N, Babson AL. A colorimetric serum glucose determination using hexokinase and glucose-6-phosphate dehydrogenase. Biochem Med. 1970;4(2):171-180.

6. Trinder P. Determination of glucose in blood using glucose oxidase with an alternative oxygen acceptor. Annals of Clinical Biochemistry. 1969;6(1):24-27.

7. Ambade VN, Sharma YV, Somani BL. Methods for Estimation of Blood Glucose : A Comparative Evaluation. Med J Armed Forces India. 1998;54(2):131-133.

8. Lange CF, Jr., Kohn P. Substrate specificity of hexokinases. J Biol Chem. 1961;236:1-5.

9. Bankar SB, Bule MV, Singhal RS, Ananthanarayan L. Glucose oxidase - an overview. Biotechnol Adv. 2009;27(4):489-501.

10. Meites S, Saniel-Banrey K. Modified glucose oxidase method for determination of glucose in whole blood. Clin Chem. 1973;19(3):308-311.

11. Wong CM, Wong KH, Chen XD. Glucose oxidase: natural occurrence, function, properties and industrial applications. Appl Microbiol Biotechnol. 2008;78(6):927-938.

12. Yoo EH, Lee SY. Glucose biosensors: an overview of use in clinical practice. Sensors (Basel). 2010;10(5):45584576.

13. Wilson CM. Quantitative determination of sugars on paper chromatograms. Analytical Chemistry. 1959;31(7):11991201.
14. Lopes JF, Gaspar EM. Simultaneous chromatographic separation of enantiomers, anomers and structural isomers of some biologically relevant monosaccharides. J Chromatogr A. 2008;1188(1):34-42.

15. Breier M, Wahl S, Prehn C, Fugmann M, Ferrari U, Weise $\mathrm{M}$, Banning F, et al. Targeted metabolomics identifies reliable and stable metabolites in human serum and plasma samples. PLoS One. 2014;9(2):e89728.

16. Miwa I, Maeda K, Okuda J. Anomeric compositions of D-glucose in tissues and blood of rat. Experientia. 1978;34(2):167-169.

17. BeMiller JN. Carbohydrate chemistry for food scientists: Saint Paul, American Association of Cereal Chemists (AACC International); 2007.

18. Sols A, Crane RK. Substrate specificity of brain hexokinase. J Biol Chem. 1954;210(2):581-595.

19. Salas M, Vinuela E, Sols A. Spontaneous and enzymatically catalyzed anomerization of glucose 6-phosphate and anomeric specificity of related enzymes. J Biol Chem. 1965;240:561-568.

20. Nelson J, Beegle FM. Mutarotation of glucose and fructose. Journal of the American Chemical Society. 1919;41(4):559-575.

21. Okuda J, Taguchi T, Tomimura A. Mutarotation of D-glucose in body fluids and perfused rat liver. Chem Pharm Bull (Tokyo). 1987;35(10):4332-4337.

22. Okuda J, Miwa I. Mutarotase effect on micro determinations of D-glucose and its anomers with $\beta$-D-glucose oxidase. Analytical Biochemistry. 1971;43(1):312-315.

23. Miwa I, Okuda J, Maeua K, Okuda G. Mutarotase effect on colorimetric determination of blood glucose with $\beta$-Dglucose oxidase. Clinica Chimica Acta. 1972;37:538-540.

24. Okuda J, Miwa I, Maeda K, Tokui K. Rapid and sensitive, colorimetric determination of the anomers of D-glucose with D-glucose oxidase, peroxidase, and mutarotase. Carbohydr Res. 1977;58(2):267-270.

25. Glick D (Ed). Methods of Biochemical Annalysis, volume 118. New York \& London, John Wiley \& Sons, 2009.

26. Preedy VR. Dietary Sugars. Chemistry, Analysis, Funtion and Effects. Food and Nutritional Components in Focus. London, Royal Society of Chemistry, 2012.

27. Oliva L, Baron C, Fernandez-Lopez JA, Remesar X, Alemany M. Marked increase in rat red blood cell membrane protein glycosylation by one-month treatment with a cafeteria diet. PeerJ. 2015;3:e1101.

28. Prats E, Monfar M, Castella J, Iglesias R, Alemany M. Energy intake of rats fed a cafeteria diet. Physiol Behav. 1989;45(2):263-272.

29. Esteve M, Rafecas I, Fernandez-Lopez JA, Remesar X, Alemany M. Fatty acid utilization by young Wistar rats fed a cafeteria diet. Mol Cell Biochem. 1992;118(1):6774.

30. Somogyi M. Determination of blood sugar. Journal of Biological Chemistry. 1945;160:69-73.

31. Leitch JM, Carruthers A. ATP-dependent sugar transport complexity in human erythrocytes. Am J Physiol Cell Physiol. 2007;292(2):C974-986.

32. Malaisse WJ, Willem R. Anomeric specificity of D-glucose production by rat hepatocytes. Mol Cell Biochem. 
2004;266(1-2):145-150.

33. Malaisse WJ, Sener A. Mathematical modelling of alpha- and beta-D-glucose metabolism in pancreatic islets exposed to equilibrated D-glucose. Int J Mol Med. 2004;14(4):677-682.

34. Zhang Y, Courtois P, Sener A, Malaisse WJ. Anomeric specificity of D-[U-14C]glucose incorporation into glycogen in rat hemidiaphragms. Biochimie. 2004;86(12):913918.

35. Malaisse WJ, Malaisse-Lagae F. Anomeric specificity of D-glucose metabolism in rat brain cells. Brain Res. 1987;419(1-2):147-155.

36. Nagata Y, Nanba T, Ando M, Miwa I, Okuda J. Anomeric preferences of D-glucose uptake and utilization by cerebral cortex slices of rats. Neurochem Res. 1979;4(4):505516.

37. Okuda J, Miwa I, Sato M, Murata T. Uptake of D-glucose anomers by rat retina. Experientia. 1977;33(1):19-20.

38. Miwa I, Fukatsu H, Toyoda Y, Okuda J. Anomeric preference of glucose utilization in human erythrocytes loaded with glucokinase. Biochem Biophys Res Commun. 1990;173(1):201-207.

39. Leitch JM, Carruthers A. alpha- and beta-monosaccharide transport in human erythrocytes. Am J Physiol Cell Physiol. 2009;296(1):C151-161.

40. Deng D, Sun P, Yan C, Ke M, Jiang X, Xiong L, Ren W, et al. Molecular basis of ligand recognition and transport by glucose transporters. Nature. 2015;526(7573):391-396.

41. Carruthers A, Melchior DL. Transport of alpha- and betaD-glucose by the intact human red cell. Biochemistry.
1985;24(15):4244-4250.

42. Zuurbier CJ, Keijzers PJ, Koeman A, Van Wezel HB, Hollmann MW. Anesthesia's effects on plasma glucose and insulin and cardiac hexokinase at similar hemodynamics and without major surgical stress in fed rats. Anesth Analg. 2008;106(1):135-142, table of contents.

43. Masek J, Fabry P. High-fat diet and the development of obesity in albino rats. Experientia. 1959;15:444-445.

44. Oliva L, Aranda T, Caviola G, Fernandez-Bernal A, Alemany M, Fernandez-Lopez JA, Remesar X. In rats fed high-energy diets, taste, rather than fat content, is the key factor increasing food intake: a comparison of a cafeteria and a lipid-supplemented standard diet. PeerJ. 2017;5:e3697.

45. Rotondo F, Ho-Palma AC, Remesar X, Fernandez-Lopez JA, Romero MDM, Alemany M. Glycerol is synthesized and secreted by adipocytes to dispose of excess glucose, via glycerogenesis and increased acyl-glycerol turnover. Sci Rep. 2017;7(1):8983.

46. Ho-Palma AC, Rotondo F, Romero MDM, FernandezLopez JA, Remesar X, Alemany M. Use of (14)C-glucose by primary cultures of mature rat epididymal adipocytes. Marked release of lactate and glycerol, but limited lipogenesis in the absence of external stimuli. Adipocyte. 2018;7(3):204-217.

47. Rotondo F, Ho-Palma AC, Remesar X, Fernandez-Lopez JA, Romero MDM, Alemany M. Effect of sex on glucose handling by adipocytes isolated from rat subcutaneous, mesenteric and perigonadal adipose tissue. PeerJ. 2018;6:e5440. 